\title{
Is health systems integration being advanced through Local Health District planning?
}

\author{
Carla Saunders ${ }^{1,2}$ PhD, MMedSc (Epi), BSc DipEd, RN, Lecturer
}

David J Carter ${ }^{1}$ LLM (Research), LLB (Hon I), BA Comms, Quentin Bryce Law Doctoral Scholar, Lecturer

${ }^{1}$ Centre for Health Services Management, Faculty of Health, University of Technology Sydney, Jones St

Ultimo 2007 (PO Box 222)

${ }^{2}$ Corresponding author. Email: carla.saunders@uts.edu.au

Objective Delivering genuine integrated health care is one of three strategic directions in the New South Wales (NSW) Government State Health Plan: Towards 2021.This study investigated the current key health service plan of each NSW Local Health District (LHD) to evaluate the extent and nature of health systems integration strategies that are currently planned.

Methods A scoping review was conducted to identify common key principles and practices for successful health systems integration to enable the development of an appraisal tool to content assess LHD strategic health service plans. Results The strategies that are planned for health systems integration across LHDs focus most often on improvements in coordination, healthcare access and care delivery for complex at-risk patients across the care continuum by both state- and commonwealth-funded systems, providers and agencies. The most common reasons given for integrated activities were to reduce avoidable hospitalisation, avoid inappropriate emergency department attendance and improve patient care.

Conclusions Despite the importance of health systems integration and finding that all NSW LHDs have made some commitment towards integration in their current strategic health plans, this analysis suggests that health systems integration is in relatively early development across New South Wales.

What is known about the topic? Effective approaches to managing complex chronic diseases have been found to involve health systems integration, which necessitates sound communication and connection between health care providers across community and hospital settings. Planning based on current health systems integration knowledge, to ensure the efficient use of scarce resources, is a responsibility of all health systems.

What does this paper add? Appropriate planning and implementation of health systems integration is becoming an increasingly important expectation and requirement of effective health systems. The present study is the first of its kind to assess the planned activity in health systems integration in the NSW public health system. NSW health districts play a central role in health systems integration; each health service plan outlines the strategic directions for the development and delivery of all state-funded services across each district for the coming years, equating to hundreds of millions of dollars in health sector funding. The inclusion of effective health systems integration strategies allows Local Health Districts to lay the foundation for quality patient outcomes and long-term financial sustainability despite projected increases in demand for health services.

What are the implications for practice? Establishing robust ongoing mechanisms for effective health systems integration is now a necessary part of health planning. The present study identifies several key areas and strategies that are wide in scope and indicative of efforts towards health systems integration, which may support Local Health Districts and other organisations in systematic planning and implementation. 


\section{Introduction}

One in five Australians is adversely affected by multiple chronic diseases. ${ }^{1}$ Chronic disease is responsible for approximately $90 \%$ of all deaths annually in Australia, with the care of patients with multiple chronic diseases accounting for the majority of healthcare costs. ${ }^{1}$ Effective approaches to managing multiple chronic diseases have been found to involve health systems integration. This requires sound communication and connection between health care providers across primary care, community and hospital settings; ${ }^{2}$ because patients, families and carers carry the principal day-to-day burden of managing chronic diseases, partnerships with these groups is also crucial. ${ }^{3-5}$ To ensure health care integration is effective, it is suggested that an integration of health research, policy and practice is similarly required. ${ }^{6,7}$ Delivering genuine integrated health care is one of three strategic directions in the New South Wales (NSW) Government State Health Plan: Towards 2021, with the NSW Ministry of Health reporting that it is '...investing in new, innovative models of integrated care, transforming the health system to routinely deliver person-centred, seamless, efficient and effective care, particularly for people with complex, long term conditions'. ${ }^{8}$

The NSW public health system includes a range of public hospital, community health and several speciality services that are administered by Local Health Districts (LHDs). ${ }^{9}$ Fifteen LHDs and two Speciality Networks report to and are funded by the NSW Ministry of Health via individual annual agreements under the provisions of the NSW Health Service Act $1997 .{ }^{10}$ The agreement supports the devolution of decision making, responsibility and accountability for the provision of safe, high-quality health care to LHDs by setting out the service and performance expectations and funding for the LHD. The agreement requires the development and delivery of a healthcare services plan that is approved by the Ministry. There is a major focus on LHDs demonstrating outcomes and value for money through several Ministry-set key performance measures not just in terms of health improvements, but also that progress is being made in health system development and advancement.

Effective health service development encompasses a sound systematic planning process to identify and meet the current and future health needs of the population within available resources. ${ }^{11,12}$ It reflects a developing social aspiration of health systems as they constantly extend their capacity to serve population health needs in effective and cost-efficient ways. The ultimate goal of health planning is to effect improvement in health services and health. Health systems integration supports this goal. Comprehensive health planning for a region is generally a continuing process of assessing current and potential future health needs and development opportunities, formulating agreed goals and objectives and developing strategies that result from identifying and appraising alternative courses of action. ${ }^{12}$ A 2013 systematic review found that joint planning between different health care provider groups, such as public and primary healthcare, including planning partnerships that span different management levels, was important for effective and sustainable health systems integration. ${ }^{13}$

The primary aim of the present study was to investigate the current health service plan of each NSW LHD to evaluate the extent and nature of the planned health systems integration activity.

\section{Methods}

A systematic multistaged methodology was used in the present study.

\section{Step 1}

A scoping review was conducted to identify common key principles and practices for successful health systems integration to enable the development of an appraisal tool to assess LHD service plans. Inclusion criteria for this scoping review were primary papers and reviews in the academic literature on health 
integration that were published in English between 2005 and August 2015 and reported one or more enablers, implementation principles and/or key dimensions of health integration, or reported an assessment of a health systems integration project or an existing appraisal tool for assessing health integration in health plans. Exclusion criteria included papers originating from the developing world, editorials, commentaries and research protocol papers. The search strategy and keywords and terms used in this review are provided in Table 1.

Keywords and terms and secondary searches yielded 197 review papers in total. The papers were assessed independently by each of the authors for eligibility for inclusion in the present study. The removal of duplicates and the exclusion of papers that did not inform one or more key common dimensions of health systems integration, papers published before 2005, non-English language papers for which translations were not available and studies set in developing countries left a total of 53 papers for full-text review.

Step 2

The key principles and practices for successful health systems integration identified from Step 1 were then used as a basis in the development of a tool to assess LHD health service plans in terms of the extent and nature of planned LHD health systems integration activity. A content analysis approach was used to analyse the LHD plans to reveal key areas of focus in terms of planned activity and provide an understanding of what progress in health systems integration may reasonably be expected over coming years in NSW. Content analysis is a research method that provides a systematic way to describe written information in terms of specific realities and consequently allows valid inferences to be made. ${ }^{14}$ Table 2 sets out the steps and related process of the content analysis undertaken for the present study.

\section{Results}

The literature on health systems integration was found to be highly diverse, with most of the individual investigations being specific and context dependent. In general, the literature reviewed either assessed the effect of integration and/or care coordination as approaches to improvements in health systems and/or tested the value of particular integration programs or initiatives across health systems for one or more clinical specialities or management areas, including information technology. Common reasons for conducting the investigations were to improve patient care and health system efficiency. No commonly agreed overarching conceptual framework for health systems integration was found; however, some key principles and practices were garnered across the literature as being important for successful health integration approaches, including shared governance, leadership, planning and/or funding; common patient pathways, protocols, management guidelines; shared and/or collaborative development of common services, programs and resources; cross-system communication and information technology interoperability; common training and education; and integration activity that is community and consumer informed and/or led. A purpose-designed appraisal tool based on these key principles and practices for successful health systems integration was used as a basis for a content analysis of the NSW LHD health service and strategic health plans. A summary of all the findings of this analysis is provided in Table 3 .

All but one LHD plan was retrieved from LHD websites and analysed. The plans had a timeframe of between 5 and 10 years, with some commencing as early as 2012. All plans had been approved by the NSW Ministry of Health. Comprehensive consultation processes involving internal and external stakeholders is reported by each LHD in the development of their respective health plans. Generally, strategic activity across all LHDs focused on LHD-specific development and although all plans report that integrated care was a key priority of the LHD and/or its board, planned activity for health integration is largely internally focused, including the need for specific district-wide integrated services, such as integrated information technology systems. Many of the LHDs describe the need to provide more efficient and effective integration of LHD acute, 
subacute and community health and clinical support services to improve patient flow, standardise care processes and establish effective ongoing relationships within the LHD. In one way or another, all plans acknowledge the growing need for cross-health systems integration, including specific integrated service delivery models with formal ties to general practice and other community services in order to properly support complex and ongoing care needs. Examples include the establishment of systems that allow patients to easily navigate and move between different health and social care providers and the recruitment of nurse care coordinators to support general practitioners in the care of patients with chronic conditions.

The strategies that are planned for health systems integration across organisations and providers most often focus on improvements in coordination, healthcare access and care delivery for complex at-risk patients across the care continuum by both state- and commonwealth-funded systems, providers and agencies. The most common reasons given for integrated activities are to reduce avoidable hospitalisation, avoid inappropriate emergency department attendance and improve patient care. One of the most frequently planned integrated care programs acknowledged in LHD plans is the NSW Chronic Disease Management Program - Connecting Care in the Community (Box 1). ${ }^{15}$ This NSW Government-funded program has been continuously implemented across NSW LHDs since 2009. The program has been shown to improve health outcomes, prevent complications and reduce the need for hospitalisation among people with chronic disease through collaborative care and chronic disease self-management support. The implementation of the program has provided important insights to LHDs into integrated care initiatives. ${ }^{16}$

Other frequently planned activities include strengthening and/or developing relationships with external groups to address health needs or gaps and to formalise new partnership arrangements with memoranda of understanding; collaborative development and/or implementation of standardised agreed care pathways and case management models; expanding or continuing existing shared care arrangements; investigating opportunities to improve patient care through timely sharing of health records and care plans, including via secure interoperable cross-system eHealth systems; and investigating and implementing strategies and/or tools to better capture community and consumer feedback and/or advance stakeholder involvement. Least frequently planned activities include region-wide health service planning; business models that support cross-system integrated service or program sustainability; region-wide networks to support the ongoing identification of health integration opportunities; working with community stakeholders to develop an improved understanding of available resources across the region, as well as the outcomes they have been shown to deliver; and developing a region-wide Telehealth plan in consultation with stakeholders to support equal patient access to specialist clinical care (for a complete summary of the findings of the content analysis, see Table 3). Overall, the least planned activity across the LHDs was in the category 'common workforce, training and education'.

\section{Discussion}

There is a high reliance on public health systems in NSW. The aging population is a significant contributor to the increasing demand for public health services, particularly for the care of ageing people with chronic complex conditions. To ensure that health care is effective and can be sustained for this growing cohort, there is an ongoing need to review and change the nature of health service provision based on effective and efficient integrated care models that support coordination between several providers across settings and service types. NSW LHDs play a central role in health systems integration; each LHD health service plan outlines the strategic directions for the development and delivery of state-funded services across each district for the coming years, equating to hundreds of millions of dollars in health sector funding. Effective health planning allows the LHDs to lay the foundation for quality patient outcomes and long-term financial 
sustainability despite projected increases in demand for health services. Establishing ongoing mechanisms for effective health systems integration is a necessary part of this planning.

The present analysis of current LHD health service plans suggests that health systems integration is in relatively early development across NSW. This has been recognised by the NSW Ministry of Health with the recent funding of the Integrated Care Strategy in 2014. ${ }^{17}$ This strategy provides funding for three LHD sites to implement local health integration demonstration models with community partners, including primary care organisations.

Planning health integration by partnering with Commonwealth Government-funded primary care has been made more difficult in recent years as a result of a series of changes to federal primary care policy, with Medicare Locals (primary care coordinating organisations) ceasing operation after a short 4-year period and new primary healthcare organisations covering much larger geographic areas needing to be established. ${ }^{18}$ However, an overarching objective of the new Primary Health Networks is to improve coordination of care, which affords a key opportunity to further develop health integration. Potential barriers to realising this opportunity have been expressed by primary care experts:

Challenges ahead include a possible government focus on delivery of 'frontline' medical services, which may come at the expense of population health, and the complexity of dealing with all primary health care stakeholders, including health professionals, Local Health Districts, nongovernment organisations, research institutions and local communities. ${ }^{19}$

Planning health integration by partnering with non-government organisations and services, which are necessary to implement integrated care models, has also been made more difficult in many rural and remote regions in NSW, with the existing number of non-government organisations and services already low and failing to grow with increasing community need. ${ }^{20-22}$

Despite the prevailing barriers that exist for effective implementation of health integration, there are opportunities for LHDs. For example, learning from the least frequently planned activities across the LHDs, there are several strategies that support the use of existing opportunities and resources, for example 'establish region-wide networks to support the ongoing identification of integration opportunities and sustain relationships with community groups and organisations' and 'work with community stakeholders to develop an improved understanding of available resources across the region, and the outcomes they have been shown to deliver'. Capturing health systems integration experiences, facilitating learning, benchmarking and showcasing workable options for integration across comparable LHDs could be routinely supported by the NSW Agency for Clinical Innovation, which has an existing role in supporting LHDs in healthcare redesign. ${ }^{23}$

There is little LHD planned strategic activity in relation to involving consumers in health systems integration planning (i.e. how LHDs intend to collect, collate and integrate consumer values and preferences in health service and delivery changes), yet involving them has been found to improve the identification of health service needs from the patient's perspective and to identify and implement strategies that are more likely to be effective to address the needs. ${ }^{24,25}$ Barriers to more widespread involvement in health service planning, and thus effective implementation, include varying interest among patients, health provider attitudes and assumptions that patients would not understand the intricacies of health planning, lack of understanding of appropriate methods for patient involvement and lack of beneficial results from previous experiences. ${ }^{26}$ One of the least planned activities across the LHDs is 'the provision of staff education/training to support improvements in the effective coordination of consumer and community involvement in health care planning'. Both the NSW Agency for Clinical Innovation and the NSW Clinical Excellence Commission ${ }^{23}$ provide support to LHDs in relation to consumer engagement across several areas. 
These agencies could further support LHDs with specific education or training in the involvement of consumers and community in health integration planning and implementation.

There are considerable and growing risks to public health service effectiveness and costs in NSW if robust LHD health integration planning strategies are not developed and implemented. However, unless those responsible for health planning at the LHD level have sound knowledge of the area, they are unlikely to fully investigate and/or incorporate effective activities into operational health plans. Providing health planners and health service managers with adequate ongoing education and training to support expert knowledge and capabilities in health systems integration will only become more important.

Securing more investment in health systems integration will largely depend on the ability to demonstrate progress in this area. Valid ways of measuring change in key dimensions of health systems integration are required to influence and maintain resource allocation. A monitoring mechanism for health systems integration would support the ability to capture trends in progress and possibly real and emerging barriers if adequate contextual information is also captured. LHD evaluation plans could incorporate some or all of the indicators for health systems integration that have been identified in this research. The generation and strategic use of research and local intelligence on health systems integration, as well as reliable health information systems, will support LHDs to ultimately achieve success in this area.

Future research could investigate the health plans of a broader range of community stakeholder groups, including the health plans of Primary Health Networks, to gain an even more extensive view of the potential for and nature of (and monitor) health integration in NSW.

\section{Conclusion}

Health systems have multiple goals, of which health systems integration is one and it is a demanding, complex process. Health systems integration is considered important to reduce the burden of chronic disease on communities and health systems. The present study identified core features of health systems integration and assessed the plans of the NSW LHDs for current and potential future progress using an evidence-based purpose-designed appraisal tool. It found that success in this area will be limited unless there is substantial ongoing support to assist LHDs to ensure health systems integration is effectively planned and embedded as common practice in our health systems. Once adequate support is available, the NSW Ministry of Health could raise the bar on health system integration performance assessment to stimulate and expedite progress in this area. The appraisal tool developed for the present study may assist health systems integration performance monitoring. To ensure that health care is effective and can be sustained for the growing cohort of aging people with chronic complex conditions, there is an ongoing need to review and change the nature of health service provision based on effective integrated care models that support coordination between several providers across settings and service types. There are considerable and growing risks to public health service effectiveness and costs in NSW if robust LHD health systems integration planning strategies are not soundly developed and implemented.

\section{Nil Competing interests}




\section{References}

1 Australian Institute of Health and Welfare. Chronic diseases. 0000. Available at: http://www.aihw.gov.au/chronic-diseases/ [verified 9 October 2015].</eref>

2 NSW Ministry of Health. Integrated care. 0000. Available at: http://www.health.nsw.gov.au/integratedcare/Pages/objectives-and-benefits.aspx [verified 9 October 2015].</eref>

3 Sherwood PR, Given CW, Given BA, Von Eye A. Caregiver burden and depressive symptoms analysis of common outcomes in caregivers of elderly patients. J Aging Health 2005; 17: 125-47. doi:10.1177/0898264304274179</jrn>

4 Uphold CR. Transitional care for older adults: the need for new approaches to support family caregivers. J Gerontol Geriatr Res 2012; 1: e107. doi:10.4172/2167-7182.1000e107</jrn>

5 Burton AM, Sautter JM, Tulsky JA, Lindquist JH, Hays JC, Olsen MK, Zimmerman SI, Steinhauser KE. Burden and well-being among a diverse sample of cancer, congestive heart failure, and chronic obstructive pulmonary disease caregivers. J Pain Symptom Manage 2012; 44: 410-20.

doi:10.1016/j.jpainsymman.2011.09.018</jrn>

6 Damschroder L, Aron DC, Keith RE, Kirsh SR, Alexander JA, Lowery JC. Fostering implementation of health services research findings into practice: a consolidated framework for advancing implementation science. Implement Sci 2009; 4: 50-65. doi:10.1186/1748-5908-4-50</jrn>

7 Stevens S, Scott I, Von Hellens L, Iselin G. 'Closing the loop': the role of health care leaders in integrating research and practice. Aust Health Rev 2004; 27: 56-64. doi:10.1071/AH042710056</jrn>

8 NSW Ministry of Health. Integrated care. 0000. Available at:

http://www.health.nsw.gov.au/integratedcare/pages/default.aspx [verified 9 October 2015].</eref>

9 NSW Government. Local Health Districts and Specialty Networks. 0000. Available at:

http://www.health.nsw.gov.au/lhd/pages/default.aspx [verified 9 October 2015].</eref>

10 NSW Ministry of Health. Service agreement. An agreement between: Secretary NSW Health and South Eastern Sydney Local Health District 1 July 2015-30 June 2016. 0000. Available at:

http://www.sesIhd.health.nsw.gov.au/docs/201516ServiceLevelAgreement.PDF [verified 9 October 2015].</eref>

11 Eagar K, Garrett P, Lin V. Health planning: Australian perspectives. Sydney: Allen \& Unwin; 2001.</bok>

12 Queensland Government. Queensland health guide to health service planning. Brisbane: Queensland Health; 2012.</bok>

13. Nicholson C, Jackson C, Marley J. A governance model for integrated primary/secondary care for the health-reforming first world - results of a systematic review. BMC Health Serv Res 2013; 13: 528 .

14 Downe-Wamboldt B. Content analysis: method, applications, and issues. Health Care Women Int 1992; 13: 313-21. doi:10.1080/07399339209516006</jrn>

15 NSW Ministry of Health. Chronic disease management program. 0000. Available at: http://www.health.nsw.gov.au/cdm/pages/default.aspx [verified 30 September 2015].</eref> 
16. State-wide evaluation NSW Health Chronic Disease Management Program. Final report October 2014. George Institute for Global Health, Centre for Primary Health Care and Equity University of New South Wales and the Centre for Health Economics Research and Evaluation at the University of Technology Sydney. 2014. Available at: http://www.health.nsw.gov.au/cdm/Documents/CDMP-Evaluation-Report2014.pdf [verified September 2015].</eref>

17 NSW Government. Integrated care strategy NSW. 0000. Available at:

http://www.health.nsw.gov.au/integratedcare/Pages/Integrated-Care-Strategy.aspx [verified 9 October 2015].</eref>

18 Commonwealth Department of Health. Primary Health Networks (PHNs). 0000. Available at: http://www.health.gov.au/internet/main/publishing.nsf/content/primary_health_networks [verified 9 October 2015].</eref>

19 Bootha M, Hilla G, Mooreb MJ, Dallab D, Moorec MG, Messengerd A. The new Australian Primary Health Networks: how will they integrate public health and primary care? Public Health Res Pract 2016; 26 (1).

20 Munn P. Factors influencing service coordination in rural South Australia. Aust Soc Work 2003; 56: 30517. doi:10.1111/j.1447-0748.2003.00093.x</jrn>

21 Barraclough F, Longman J, Barclay L. Integration in a nurse practitioner-led mental health service in rural Australia. Aust J Rural Health 2015. doi:10.1111/ajr.12233</jrn>

22 Platt V, O'Connor K, Coleman R. Improving regional and rural cancer services in Western Australia. Aust J Rural Health 2015; 23: 32-9. doi:10.1111/ajr.12171</jrn>

23 NSW Agency for Clinical Innovation. Models of care. . 0000. Available at:

http://www.aci.health.nsw.gov.au/resources/models-of-care [verified 9 October 2015].</eref>

24 Wiseman V, Mooney G, Berry G, Tang KC. Involving the general public in priority setting: experiences from Australia. Soc Sci Med 2003; 56: 1001-12. doi:10.1016/S0277-9536(02)00091-6</jrn>

25 Abelson J, Forest PG, Casebeer A, Mackean G, The Effective Public Consultation Project Team. Will it make a difference if I show up and share? A citizen's perspective on improving public involvement processes for health system decision-making. J Health Serv Res Policy 2004; 9: 205-12. doi:10.1258/1355819042250203</jrn>

26 Gagliardi AR, Lemieux-Charles L, Brown AD, Sullivan T, Goel V. Barriers to patient involvement in health service planning and evaluation: an exploratory study. Patient Educ Couns 2008; 70: 234-41. doi:10.1016/i.pec.2007.09.009</jrn>

27 NSW Clinical Excellence Commission. Partnering with patients program. 0000. Available at: http://www.cec.health.nsw.gov.au/programs/partnering-with-patients [verified 9 October 2015].</eref>

28 Suter E, Oelke ND, Adair CE, Armitage GD. Ten key principles for successful health systems integration. Healthc Q 2009; 13: 16-23. doi:10.12927/hcq.2009.21092</jrn>

29 Nicholson C, Jackson C, Marley J. A governance model for integrated primary/secondary care for the health-reforming first world: results of a systematic review. BMC Health Serv Res 2013; 13: 528-536. doi:10.1186/1472-6963-13-528</jrn>

30 Oelke ND, Cunning L, Andrews K, Martin D, MacKay A, Kuschminder K, Congdon V. Organizing care across the continuum: primary care, specialty services, acute and long-term care. Healthc Q 2009; 13: 75-9. doi:10.12927/hcq.2009.21102</jrn> 
31 Fortin M, Chouinard MC, Bouhali T, Dubois MF, Gagnon C, Bélanger M. Evaluating the integration of chronic disease prevention and management services into primary health care. BMC Health Serv Res 2013; 13: 132. doi:10.1186/1472-6963-13-132</jrn>

32 Thielke S, Vannoy S, Unützer J. Integrating mental health and primary care. Prim Care 2007; 34: 571-92. doi:10.1016/i.pop.2007.05.007</jrn>

33 Letourneau S. Health Link Alberta: a model for successful health service integration. Healthc Q 2009; 13: 56-60. doi:10.12927/hcq.2009.21099</jrn>

34 Bichel A, Erfle S, Wiebe V, Axelrod D, Conly J. Improving patient access to medical services: preventing the patient from being lost in translation. Healthc Q 2009; 13: 61-8. doi:10.12927/hcq.2009.21100 35 Brailer DJ. Interoperability: the key to the future health care system. Health Affairs 2005; 24-27: W5.

Table 1. Search strategy summary

\footnotetext{
Search strategy

Papers published from 2005 to April 2015 (those published before 2005 assessed if necessary to complete a picture)

Databases: Scopus, PubMed, Medline, Embase, CINAHL, PsycINFO and Informit

Manual searches of reference sections and citations of relevant textbooks and journal articles

Manual searches of major appropriate journals, such as the International Journal of Integrated Care, Topics in Integrative Health Care and Journal of Integrated Care

Key words/terms

Integration OR care coordination OR shared care OR collaboration

Healthcare OR health service OR health organization/organisation OR health system OR health institution OR health agency

Implement OR execute OR conduct

Evaluate OR assess OR measure
} 
Table 2. Content analysis process

The content analysis process used in the present study was adapted from Downe-Wamboldt.14 LHD, Local Health District; NSW, New South Wales

\begin{tabular}{|l|l|}
\hline $\begin{array}{l}\text { 1. Select information to be } \\
\text { analysed }\end{array}$ & Current LHD health service and/or strategic health plans \\
\hline $\begin{array}{l}\text { 2. Define the information sets of } \\
\text { interest }\end{array}$ & $\begin{array}{l}\text { All planned activities, strategies, actions provided in NSW LHD } \\
\text { health service and/or strategic health plans were analysed and } \\
\text { categorised according to the key principles and practices of health } \\
\text { systems integration identified from Step 1. Specific attributes were } \\
\text { developed, via examples of each of these categories, to distinguish } \\
\text { the similarities and differences between categories (Table 3). Two } \\
\text { subcategories were then used to further define the results within } \\
\text { each category (i.e. 'most frequently planned activity' and 'least } \\
\text { frequently planned activity'). }\end{array}$ \\
\hline $\begin{array}{l}\text { 3. Pretest category and sub- } \\
\text { category definitions }\end{array}$ & $\begin{array}{l}\text { Initial detailed scrutiny of two LHD health service and/or strategic } \\
\text { health plans was undertaken to determine structure, placement, } \\
\text { wording and detail of planned activities, strategies and actions. } \\
\text { Categories and subcategories were tested with the activities from } \\
\text { the two plans and were found to be applicable. The use of these } \\
\text { categories was then assessed on an ongoing basis throughout the } \\
\text { research. }\end{array}$ \\
\hline 4. Assess reliability and validity & $\begin{array}{l}\text { A single occurrence was identified when the defined subcategories } \\
\text { could not be used (i.e. when an activity relevant to only one } \\
\text { category was planned by a lone LHD). This is clarified within the } \\
\text { findings in Table 3. }\end{array}$ \\
\hline
\end{tabular}




\section{Table 3. NSW Local Health District (LHD) planned integration activity}

NGO, non-governmental organisation; NSW, New South Wales; GP, general practitioner

\begin{tabular}{|c|c|}
\hline $\begin{array}{l}\text { Key principles or practices for successful health system } \\
\text { integration }\end{array}$ & NSW LHD planned activity to support health system integration ${ }^{A}$ \\
\hline $\begin{array}{l}\text { Shared governance, leadership, planning and/or funding }{ }^{24,25} \\
\text { such as: }\end{array}$ & Most frequently planned activities: \\
\hline $\begin{array}{l}\text { - Links and/or similarities between goals, vision and mission } \\
\text { across organisations }\end{array}$ & $\begin{array}{l}\text { - Strengthen and/or develop relationships with external groups to address specific } \\
\text { needs and/or health service issues and/or gaps and/or generate opportunities }\end{array}$ \\
\hline $\begin{array}{l}\text { - A shared strategic mission that focuses on linking funding, } \\
\text { workforce, technology and/or services across systems }\end{array}$ & - Reciprocal Board and/or Executive Committee membership \\
\hline $\begin{array}{l}\text { - Supra or overarching governance structures that cross } \\
\text { health systems to provide a high level of oversight or } \\
\text { advisory on health system integration }\end{array}$ & $\begin{array}{l}\text { - Formalise existing or establish new partnership arrangements or collaborations } \\
\text { memoranda of understanding and/or service agreements that outline how each } \\
\text { organisation will work together to address one or more common agreed health pri } \\
\text { particular reasons given for these contractual arrangements include to: }\end{array}$ \\
\hline $\begin{array}{l}\text { - Cross-system representation on boards and executive } \\
\text { committees }\end{array}$ & O reduce service duplication \\
\hline $\begin{array}{l}\text { - Pooled funding for one or more common programs, } \\
\text { services or initiatives }\end{array}$ & $\begin{array}{l}\text { improve care and support for people with chronic disease, Aboriginal } \\
\text { populations and other specific groups }\end{array}$ \\
\hline $\begin{array}{l}\text { - Collaborative multisystem plans that align with identified } \\
\text { needs through stages in the patient journey (i.e. patient } \\
\text { movements within and between systems) }\end{array}$ & ○ increase, improve or initiate coordinated care across systems \\
\hline $\begin{array}{l}\text { - Joint proposal development, application and } \\
\text { implementation of grant-funded projects }\end{array}$ & ○ support program implementation \\
\hline & ○ support the implementation of population health actions \\
\hline & - promote greater integration with primary care \\
\hline
\end{tabular}

Page 11 of 17 
- enhance access to integrated models of care

- Establish interagency or interorganisation committees

- Review existing LHD service delivery approaches to identify opportunities to reduce demand for acute care via broader health system involvement

Least frequently planned activities:

- Region-wide clinical governance framework development

- Region-wide health service planning

- Business models that support cross-system integrated service and/or program sustainability

- Collaborative community health needs assessments

- Regular review of existing health service plans to ensure they align with emerging models and approaches for effective health system integration

- Establishing region-wide networks to support the ongoing identification of integration opportunities and sustain relationships with community groups and organisations

- Work with community stakeholders to develop an improved understanding of available resources across the region, and the outcomes they have been shown to deliver

Common patient pathways, transfers and management guidelines, ${ }^{26,27}$ such as:

- Cross-system care pathways that align with identified patient needs at different stages in the care journey (i.e. patient movements within and between systems)
Most frequently planned activities:

- The collaborative development and/or implementation of standardised agreed care pathways and case management models across health and/or NGO and/or social services to improve care coordination and simplify access and referral to services for patients and clinicians 
- Process changes aimed at streamlining patient navigation across systems and services

Shared and/or collaborative development of common services, programs, models of care and resources, ${ }^{28-30}$ such as:

- Activities, programs and/or services that coordinate activity across the care continuum

- Investigations and activities that identify and reduce duplicative services, programs and/or resources
- Review relevant state-wide and other LHD chronic disease management pathways, models and protocols to support local implementation of effective and timely care coordination across providers and services

- Review existing discharge and/or transition care planning processes and identify and act on opportunities for improvements

Least frequently planned activities:

- Establish opportunities for public, private and primary care clinicians to work together to improve discharge and referral processes

- Work with partner organisations to identify workable approaches to ensure patient and family involvement in the development and review of care pathways

Most frequently planned activities:

- Continue existing or improve collaborative approaches among a range of stakeholders to support general practice and residential aged care to reduce avoidable hospitalisation

- Implement and/or expand the NSW Government Connecting Care program

- Implement, expand or continue shared care arrangements, such as GP antenatal shared care programs

- Enhance existing outreach initiatives from acute settings to residential aged care facilities

- Nurse care coordinators to support general practitioners and to facilitate ongoing support for patients with chronic conditions

Least frequently planned activities: 
- Establish or expand a HealthOne service in collaboration with community organisations and providers

- Identify opportunities for collocation of care services to improve access to care

- Collaborative community asset mapping to identify opportunities to keep people well and out of hospital

- Establishment of integrated service provision early intervention ambulatory and outreach clinics for patients with complex chronic conditions

- Work with health and non-health transport services to improve timely access to health services

- Development of new shared care models or services (e.g. for palliative care patients)

Cross-system/organisation eCommunication and information technology interoperability, ${ }^{31,32}$ such as:

- Activities and incentives to promote the establishment of cooperative working relationships across systems

- The establishment of information systems that link patients and/or providers across systems

- Standard, direct communication channels and practices that efficiently transfer information across system and organisational boundaries

- Activities to establish cross-system oversight of information systems to ensure ongoing compatibility and interoperability
Most frequently planned activities:

- Investigate opportunities to improve patient care and support and improve clinical decision making through timely communication and sharing of health records and care plans, including via secure interoperable cross-system eHealth information systems

- Enhance the role of Telehealth to further improve efficiency and local access to specialist clinical services (e.g. local GPs and patient's link to specialist clinicians or teams via Telehealth facilities)

- Trial and/or implement home telemonitoring to support patients with chronic and complex conditions to better monitor and manage their own health

- Establish an information call line to provide specialist support to GPs in the care of patients with complex chronic disease

Least frequently planned activities: 
Common workforce, training and education, ${ }^{33-35}$ such as:

- Cross-system professional practice training or education, networking and support activities

- Region-wide workforce planning to support the identification of current and anticipated gaps in the workforce and identify workable shared workforce models and strategies to attract workforce

Integration activity that has community or consumer involvement or is community or consumer informed, ${ }^{20,21}$ such as:

- Community or consumer involvement in integration efforts or engagement to specifically inform integration efforts

- Community-informed needs assessment drives health system integration activities
- In collaboration with all relevant stakeholders, develop a region-wide information technology strategic plan to support improvements in patient care and support

- Review the current use and impact of Telehealth, and identify and develop a framework that indicates where most benefit can be gained from its application within existing region-wide capacity and expertise

- Develop a region-wide Telehealth plan in consultation with stakeholders that ensures equal patient access to specialist clinical care

- Expand the use of technology to include apps that have been shown to support patients in chronic disease management, aid secondary prevention and/or support patient well being

Strategies planned by single LHDs:

- In collaboration with stakeholders, develop a region-wide multidisciplinary health education and training strategic plan that targets key clinical education and training needs across the region and enhances ongoing clinician relationships and networks

- Partner with stakeholders, including the tertiary education sector, to identify and provide cross-sectoral opportunities for inter-professional practice, education and research

Most frequently planned activities:

- Develop and/or review the communications plan to support effective two-way communication with external stakeholders and the community, including the use of social marketing, purpose-designed apps etc.

- Investigate and implement strategies and/or tools to better capture community and consumer feedback and/or advance stakeholder involvement 
- Investigations with patients of collaborations that are most likely to maximise the value of services delivered to patients
- Develop, review and/or enhance the community participation framework and/or consumer committees to ensure there is effective engagement with the local community

Least frequently planned activities:

- Maintain a staff education or training program to support improvements across the organisation in the effective coordination of consumer and community involvement

- Establish community participation networks to facilitate region-wide consumer and community engagement on issues that cross systems and services

- Coordinate and implement a region-wide patient-centred care and support framework

${ }^{A}$ Activities from LHD Health Service Plans have been rephrased as required for clarity and readability; they retain the original meaning or intention. 


\section{Box 1. Chronic Disease Management Program: Connecting Care in the Community}

The New South Wales Ministry of Health Chronic Disease Management Program Connecting Care in the Community provides care coordination and self-management support to help eligible groups with chronic disease to better manage their condition/s and access appropriate services in order to improve health outcomes, prevent complications and reduce the need for hospitalisation. In 2011, The George Institute performed an independent state-wide review of the Chronic Disease Management Program. Detailed information on this program and its evaluation are available at:

http://www.health.nsw.gov.au/cdm/pages/default.aspx (accessed 28/02/2016). 